\title{
Job satisfaction among Syrian healthcare workers in refugee health centres
}

\author{
Monica Zikusooka ${ }^{1 *}$ (D) Omur Cinar Elci ${ }^{1}$ and Habibe Özdemir ${ }^{2}$
}

\begin{abstract}
Background: Achieving universal health coverage is subject to the availability, accessibility, acceptability, and quality of health workers. Countries that host refugees and migrants, such as Turkey, must strengthen the capacity of their health systems to increase access to services, especially for refugees and migrants. The Turkish Ministry of Health adapted Syrian refugee healthcare workers in the healthcare services to boost Syrian refugees' access to healthcare. This study aimed to assess job satisfaction and the factors influencing job satisfaction among refugee physicians and nurses working in Refugee Healthcentres (RHCs) in Turkey.

Methods: A self-administered, cross-sectional survey targeted all Syrian physicians and nurses working in RHCs across Turkey. The short-form Minnesota Satisfaction Questionnaire(MSQ) was used to assess job satisfaction. In total, 555 nurse/midwives and 336 physicians responded, yielding a total response rate of 56.5\%. Descriptive analyses and linear regression tests were conducted to determine the level of job satisfaction and to analyze determinant factors.

Results: Nurses/midwives reported the highest level of general job satisfaction, followed by specialist physicians and general physicians. Physicians who had worked as specialists in Syria but were now working as general physicians in Turkey had the lowest job satisfaction levels. Multiple regression analysis showed that professional status in Turkey, income, teamwork and team management were significantly associated with job satisfaction.
\end{abstract}

Conclusions: To maintain a high level of job satisfaction in refugee healthcare workers, human resources management should consider matching job placements with training specialization and support good leadership and good teamwork. Remuneration that accounts for the cost of living and non-financial incentives could also play a significant role in job satisfaction.

Keywords: Job satisfaction, Healthcare, Health workers, Physicians, Refugee, Migrant, Nurses, Turkey

\section{Introduction}

Turkey hosts almost 3.7 million Syrian Refugees [1]. To meet the healthcare needs of the refugee population and to relieve pressure on the national health system workforce, the Ministry of Health $(\mathrm{MoH})$ of the Republic of Turkey, established Refugee Healthcentres (RHCs), where Syrian healthcare workers (SHW) provide culturally and linguistically sensitive primary healthcare services.

*Correspondence: zikusookam@who.int

${ }^{1}$ Refugee Health Programme, WHO Country Office in Turkey, WHO Regional Office for Europe, Ankara, Turkey

Full list of author information is available at the end of the article
WHO, in collaboration with the $\mathrm{MoH}$, implemented an adaptation training program to adapt qualified SHW to the Turkish healthcare system before employment in RHCs. SHW are authorized to work only in RHCs, where patients are only refugees or migrants, mainly Syrian refugees. RHCs may provide primary health services, such as vaccination, maternal and childcare services, and emergency health services to other migrant nationalities. Turkish nationals do not receive healthcare services from RHCs. Syrian nurses, midwives and general physicians work at the same level as they did in Syria, but according to regulatory procedures, specialist physicians are mainly employed as general physicians; only a small proportion original author(s) and the source, provide a link to the Creative Commons licence, and indicate if changes were made. The images or other third party material in this article are included in the article's Creative Commons licence, unless indicated otherwise in a credit line to the material. If material is not included in the article's Creative Commons licence and your intended use is not permitted by statutory regulation or exceeds the permitted use, you will need to obtain permission directly from the copyright holder. To view a copy of this licence, visit http://creativecommons.org/licenses/by/4.0/. The Creative Commons Public Domain Dedication waiver (http://creativeco mmons.org/publicdomain/zero/1.0/) applies to the data made available in this article, unless otherwise stated in a credit line to the data. 
continue to work as specialists. Syrian physicians in RHCs are paid the same wages as Turkish physicians working in primary healthcare services.

Refugee health workers face multiple challenges in continuing their profession while in host countries. Foremost is the lengthy and complex recognition process, which requires complex documentation and might face mismatched equivalency [2-5]. Yet, retraining is time, labor, and financially demanding against other family needs and stressors of migration [5-7]. As a result, some health workers may change to fields requiring fewer qualifications leading to underemployment $[3,8]$, a lost opportunity for the host country to address potential healthcare worker shortages and diversify the workforce [9]. Deskilling of healthcare workers disproportionally affects women [10]. Unable to continue their profession, health workers face professional disappointment and psychological effects $[11,12]$. Some countries offer training and placement programs to fast track the integration of refugees $[3,7,13,14]$; however, their successes are diffident [12-14]. Refugee and migrant health workers also face other barriers ranging from unfamiliarly with the health care system [15], different working cultures, and discrimination from patients and co-workers $[3,4]$. Notwithstanding, refugee and other migrant healthcare workers present a valuable health workforce in host countries $[16$, 17].

Studies have shown that physicians' satisfaction with their work and work environment may impact the quality of healthcare [18], patients' satisfaction with their healthcare [19-22], patients' adherence to medical instructions [23] and physicians' commitment and retainment $[18,24]$. The higher turnover rates for physicians due to poor job satisfaction may disrupt care provision and access to healthcare, while recruitment and replacement efforts may increase healthcare costs. Some factors affecting job satisfaction relate to the individual, such as age, gender, marital status, and work experience, while others are intrinsic to the nature of the job, such as specialization, patient interactions, and work engagement [25]. Yet, other factors can relate to the job context, such as workload, job security, and income level, or the work environment, such as the type of facility, management, professional development, teamwork, and access to resources [25]. Job satisfaction among nurses may be influenced by the work environment, workload, team support, stress and emotional exhaustion and ethnicity [26-29]. Job satisfaction among nurses has also been negatively associated with turnover $[24,27,30]$.

Not as many studies have investigated job satisfaction among refugee healthcare workers as among migrant healthcare workers. Moreover, existing evidence on refugee and migrant healthcare workers largely relates to integration into the host country's health system to provide services to the host population. However, in a unique structure in the Turkish health system, Syrian refugee healthcare workers provide culturally and languagesensitive services only to the Syrian refugee population through the RHCs mechanism. Although there might be similarities between the experiences of Syrian refugee healthcare workers in Turkey and refugee healthcare workers elsewhere, understanding job satisfaction in this unique context could contribute to human resource planning in countries with large refugee and migrant populations. This study sought to establish job satisfaction and identify the factors that determine job satisfaction among Syrian physicians and nurses working in RHCs in Turkey.

\section{Method}

Data was collected using a self-administered, crosssectional survey that targeted all Syrian physicians and nurses working in RHCs across Turkey. Job satisfaction was assessed using the General Job Satisfaction scale based on the short-form MSQ [31]. After reviewing various other tools to measure job satisfaction, short-form MSQ fit best with the work structure, job descriptions, and the aim of the study. The short-form MSQ included 20 items on job satisfaction: ability utilization, achievement, activity, advancement, authority, company policies, compensation, co-workers, creativity, independence, moral values, recognition, responsibility, security, social status, social service, supervision-human relations, supervision-technical, variety and working conditions. The determinants of job satisfaction were assessed using a separate questionnaire that was developed following a review of WHO field assessments in Turkey supported by a literature review on factors influencing job satisfaction in healthcare workers. The final combined questionnaire was translated from English to Arabic and then retranslated to English for consistency in the meaning of the questions. The final Arabic questionnaire was pretested to check the suitability of the Syrian Arabic dialect, clarity of content, and interpretation of questions.

\section{Sample and data collection}

According to the MoH data, 681 Syrian physicians and 896 nurses were employed in RHCs across Turkey at the time of the survey. Between October and November 2019, an electronic link to the online questionnaire was sent to all physicians and nurses working in RHCs. The Department of Migration, $\mathrm{MoH}$, through the medical directors in each RHC, sent weekly reminders to the healthcare workers for their participation. In total, 555 nurse/midwives and 336 physicians, giving an overall response rate of $56.5 \%$ (61.9\% for nurses and $49.3 \%$ for physicians), completed the questionnaire. 


\section{Data analysis}

A descriptive analysis was conducted to summarize the distribution of the study population and determine the level of job satisfaction. Due to the non-parametric nature of the data, the inferential relationship between variables and the job satisfaction score was assessed using the Mann-Whitney U and the Kruskal-Wallis tests. For variables that had three groups, Dunn's pairwise tests with adjustment using Bonferroni correction were conducted after the Kruskal-Wallis test to identify groups with significantly different levels of job satisfaction. Linear regression analysis was also conducted to determine the factors that influenced job satisfaction. Data were analyzed using IBM SPSS Statistics version 25.0.

\section{Results}

Most of the participants were nurses/midwives (62\%). Approximately two-thirds of respondents were men (65.2\%), 56.7\% were younger than 40 , and $86.9 \%$ were married. Mostly physicians, $47.3 \%$ of participants were Syrians with Turkish citizenship (Table 1). Although most of the healthcare workers had an undergraduate degree or higher, for $28.8 \%$ of nurses, the highest education level was high school. Almost half (41.2\%) of study participants had five or fewer years of work experience in Syria, and $64.5 \%$ had worked in Turkish healthcare services for 2 years or less.

\section{Work characteristics and work environment}

Almost half of the nurses/midwives (46.1\%) reported seeing an average of 21-40 patients per day; in comparison, the highest proportions of both general and specialist physicians reported seeing more than 61 patients per day (46.7\% and $39.0 \%$, respectively) (Table 2 ). Most participants reported having access to the resources required for their work and knowing how to use the equipment and materials at their disposal. Among all participants, $88.2 \%$ rated the level of teamwork as good. A slightly

Table 1 Sociodemographic and occupational characteristics of respondents

\begin{tabular}{|c|c|c|c|c|c|c|c|c|}
\hline \multirow[t]{2}{*}{ Characteristic } & \multicolumn{2}{|c|}{$\begin{array}{l}\text { General physician } \\
(n=259)\end{array}$} & \multicolumn{2}{|c|}{$\begin{array}{l}\text { Specialist physician } \\
(n=77)\end{array}$} & \multicolumn{2}{|c|}{ Nurse/midwife $(n=555)$} & \multicolumn{2}{|c|}{ Total $(n=891)$} \\
\hline & $n$ & $\%$ & $n$ & $\%$ & $n$ & $\%$ & $n$ & $\%$ \\
\hline \multicolumn{9}{|l|}{ Sex } \\
\hline Male & 209 & 80.7 & 58 & 75.3 & 314 & 56.6 & 581 & 65.2 \\
\hline Female & 50 & 19.3 & 19 & 24.7 & 241 & 43.4 & 310 & 34.8 \\
\hline \multicolumn{9}{|l|}{ Age group (years) } \\
\hline $20-29$ & 41 & 15.8 & 0 & 0.0 & 127 & 22.9 & 168 & 18.9 \\
\hline $30-39$ & 100 & 38.6 & 24 & 31.2 & 213 & 38.4 & 337 & 37.8 \\
\hline $40-49$ & 56 & 21.6 & 34 & 44.2 & 159 & 28.6 & 249 & 27.9 \\
\hline$\geq 50$ & 62 & 23.9 & 19 & 24.7 & 56 & 10.1 & 137 & 15.4 \\
\hline \multicolumn{9}{|l|}{ Nationality } \\
\hline Syrian & 111 & 42.9 & 31 & 40.3 & 328 & 59.1 & 470 & 52.7 \\
\hline Syrian with Turkish citizenship & 148 & 57.1 & 46 & 59.7 & 227 & 40.9 & 421 & 47.3 \\
\hline \multicolumn{9}{|l|}{ Education } \\
\hline High school & 0 & 0.0 & 0 & 0.0 & 160 & 28.8 & 160 & 18.0 \\
\hline Undergraduate degree & 166 & 64.1 & 16 & 20.8 & 386 & 69.5 & 568 & 63.7 \\
\hline Masters/postgraduate degree & 93 & 35.9 & 61 & 79.2 & 9 & 1.6 & 163 & 18.3 \\
\hline \multicolumn{9}{|l|}{ Profession in Syria } \\
\hline General physician & 184 & 71.0 & 0 & 0.0 & 0 & 0.0 & 184 & 20.7 \\
\hline Specialist physician & 75 & 29.0 & 77 & 100.0 & 0 & 0.0 & 152 & 17.1 \\
\hline Nurse/midwife & 0 & 0.0 & 0 & 0.0 & 555 & 100.0 & 555 & 62.3 \\
\hline \multicolumn{9}{|l|}{ Years worked in Syria } \\
\hline $0-5$ & 134 & 51.7 & 20 & 26.0 & 213 & 38.4 & 367 & 41.2 \\
\hline $6-10$ & 53 & 20.5 & 21 & 27.3 & 123 & 22.2 & 197 & 22.1 \\
\hline$>10$ & 72 & 27.8 & 36 & 46.8 & 219 & 39.5 & 327 & 36.7 \\
\hline \multicolumn{9}{|l|}{ Years worked in Turkey ${ }^{a}$} \\
\hline $0-2$ & 172 & 66.4 & 42 & 54.5 & 361 & 65.0 & 575 & 64.5 \\
\hline$>2$ & 87 & 33.6 & 35 & 45.5 & 194 & 35.0 & 316 & 35.5 \\
\hline
\end{tabular}

${ }^{\mathrm{a}}$ In the Ministry of Health project 
Table 2 Work characteristics and work environment of respondents

\begin{tabular}{|c|c|c|c|c|c|c|c|c|c|}
\hline \multirow[t]{2}{*}{ Characteristic } & \multicolumn{3}{|c|}{ General physician $(n=259)$} & \multicolumn{2}{|c|}{$\begin{array}{l}\text { Specialist physician } \\
(n=77)\end{array}$} & \multicolumn{2}{|c|}{ Nurse/midwife $(n=555)$} & \multicolumn{2}{|c|}{ Total $(n=891)$} \\
\hline & $n$ & & $\%$ & $n$ & $\%$ & $n$ & $\%$ & $n$ & $\%$ \\
\hline \multicolumn{10}{|c|}{ Type of health centre } \\
\hline RHTC & & 23 & 8.9 & 11 & 14.3 & 42 & 7.6 & 76 & 8.5 \\
\hline $\mathrm{RHC}$ & & 215 & 83.0 & 56 & 72.7 & 491 & 88.5 & 762 & 85.5 \\
\hline Extended RHC & & 21 & 8.1 & 10 & 13.0 & 22 & 4.0 & 53 & 5.9 \\
\hline \multicolumn{10}{|c|}{ Average number of patients/day } \\
\hline$<21$ & 3 & & 1.2 & 3 & 3.9 & 68 & 12.3 & 74 & 8.3 \\
\hline $21-40$ & 40 & & 15.4 & 18 & 23.4 & 256 & 46.1 & 314 & 35.2 \\
\hline $41-60$ & 95 & & 36.7 & 26 & 33.8 & 153 & 27.6 & 274 & 30.8 \\
\hline$\geq 61$ & 121 & & 46.7 & 30 & 39.0 & 78 & 14.1 & 229 & 25.7 \\
\hline \multicolumn{10}{|c|}{ Access to resources needed for work } \\
\hline Yes & 196 & & 75.7 & 49 & 63.6 & 489 & 88.1 & 734 & 82.4 \\
\hline No & 63 & & 24.3 & 28 & 36.4 & 66 & 11.9 & 157 & 17.6 \\
\hline \multicolumn{10}{|c|}{ Know how to use equipment/other materials } \\
\hline Yes & 256 & & 98.8 & 77 & 100.0 & 551 & 99.3 & 884 & 99.2 \\
\hline No & 3 & & 1.2 & 0 & 0.0 & 4 & 0.7 & 7 & 0.8 \\
\hline \multicolumn{10}{|l|}{ Teamwork } \\
\hline Poor & 11 & & 4.2 & 2 & 2.6 & 8 & 1.4 & 21 & 2.4 \\
\hline Average & 34 & & 13.1 & 7 & 9.1 & 43 & 7.7 & 84 & 9.4 \\
\hline Good & 214 & & 82.6 & 68 & 88.3 & 504 & 90.8 & 786 & 88.2 \\
\hline \multicolumn{10}{|c|}{ Team management } \\
\hline Poor & 34 & & 13.1 & 8 & 10.4 & 27 & 4.9 & 69 & 7.7 \\
\hline Average & 49 & & 18.9 & 15 & 19.5 & 66 & 11.9 & 130 & 14.6 \\
\hline Good & 176 & & 68.0 & 54 & 70.1 & 462 & 83.2 & 692 & 77.7 \\
\hline \multicolumn{10}{|l|}{ Income } \\
\hline Poor & 118 & & 45.6 & 23 & 29.9 & 73 & 13.2 & 214 & 24.0 \\
\hline Average & 111 & & 42.9 & 43 & 55.8 & 257 & 46.3 & 411 & 46.1 \\
\hline Good & 30 & & 11.6 & 11 & 14.3 & 225 & 40.5 & 266 & 29.9 \\
\hline
\end{tabular}

lower proportion of all participants (77.7\%) rated their team management as good; the lowest proportion of participants giving this assessment were general physicians (68.0\%). Of the three professional groups, nurses were the most positive about their teamwork and team management. Overall, $46.1 \%$ of participants rated their income as average; this rating was reflected among the specialist physicians and nurses, while the highest proportion of general physicians assessed their income as poor.

\section{Job satisfaction}

Nurses/midwives reported the highest level of general job satisfaction, followed by specialist physicians and then general physicians (Table 3). Kruskal-Wallis analysis provided strong support that job satisfaction levels differed between the three professional groups $(p<0.001)$; a follow-up Dunn's pairwise test revealed that job satisfaction scores were significantly higher in nurses than in physicians, both general and specialist $(p<0.001)$. Further
Table 3 Job satisfaction by profession

\begin{tabular}{llllll}
\hline Profession & $\begin{array}{l}\text { Participants } \\
(\boldsymbol{n})\end{array}$ & Mean & SD & $\mathbf{9 5 \%} \mathbf{C l}$ & Range \\
\hline $\begin{array}{l}\text { General physi- } \\
\text { cian }\end{array}$ & 259 & 63.3 & 14.6 & $61.5-65.1$ & $20.0-100.0$ \\
$\begin{array}{l}\text { Specialist physi- } \\
\text { cian }\end{array}$ & 77 & 65.9 & 13.2 & $63.2-69.0$ & $29.0-88.0$ \\
$\begin{array}{l}\text { Nurse/midwife } \\
\text { Total }\end{array}$ & 555 & 74.9 & 11.0 & $74.0-75.8$ & $20.0-100.0$ \\
\hline
\end{tabular}

analysis revealed that physicians who had worked as specialists in Syria but were now working as general physicians in Turkey had the lowest satisfaction levels (Fig. 1). However, the difference in job satisfaction between subgroups of physicians was not significant.

As there was no significant difference in job satisfaction between general and specialist physicians, data for 


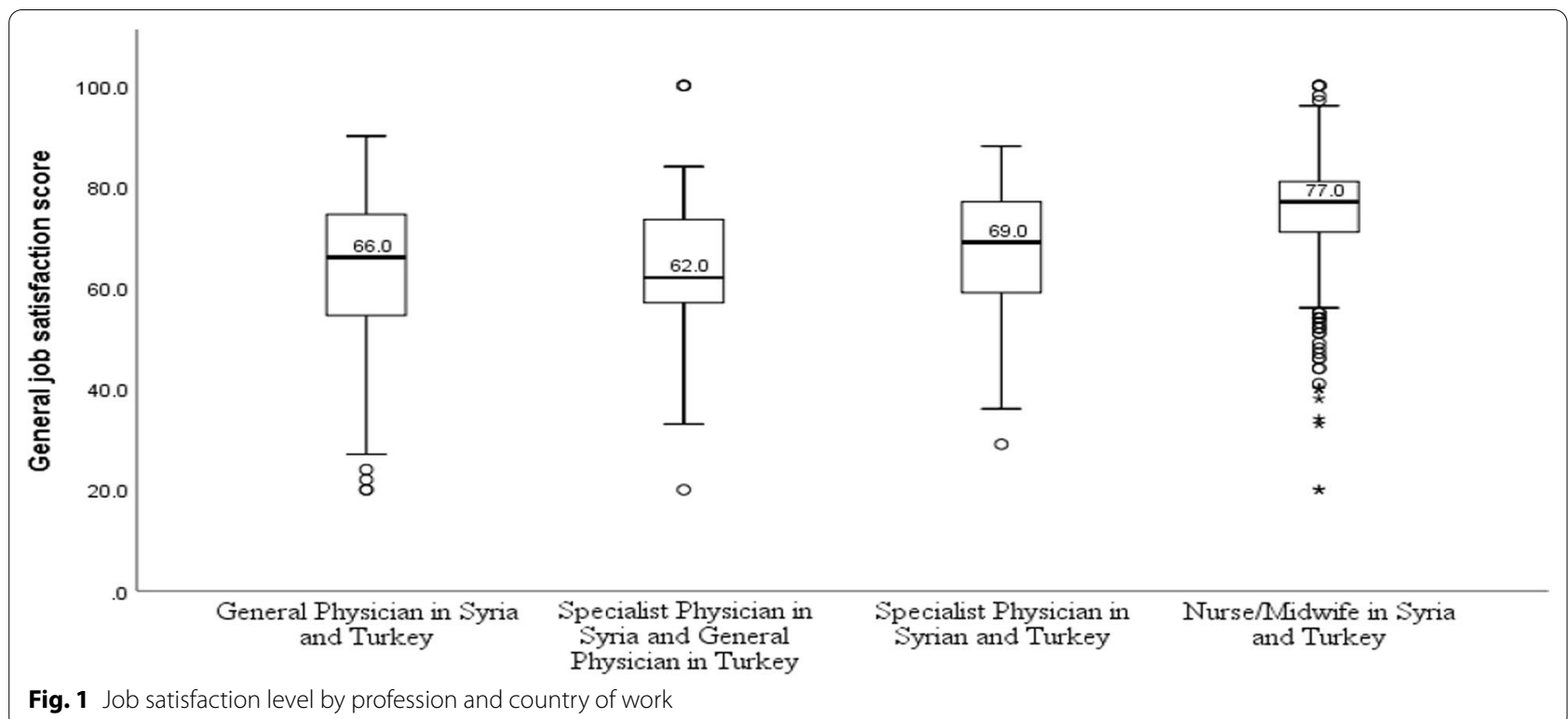

both groups were combined in the analysis of satisfaction on the items of the MSQ. Levels of satisfaction on the 20 items on the MSQ also varied among the different groups of participants (Figs. 2 and 3). Responses for the five-point Likert scale were combined into three categories: satisfied (satisfied and very satisfied), neutral and dissatisfied (dissatisfied and very dissatisfied).
Physicians were most satisfied with the co-workers, authority and social service items and least satisfied with the compensation, workplace policy/practice and moral values items. Nurses were most satisfied with the social services, professional ability utilization, and co-workers and least satisfied with the moral

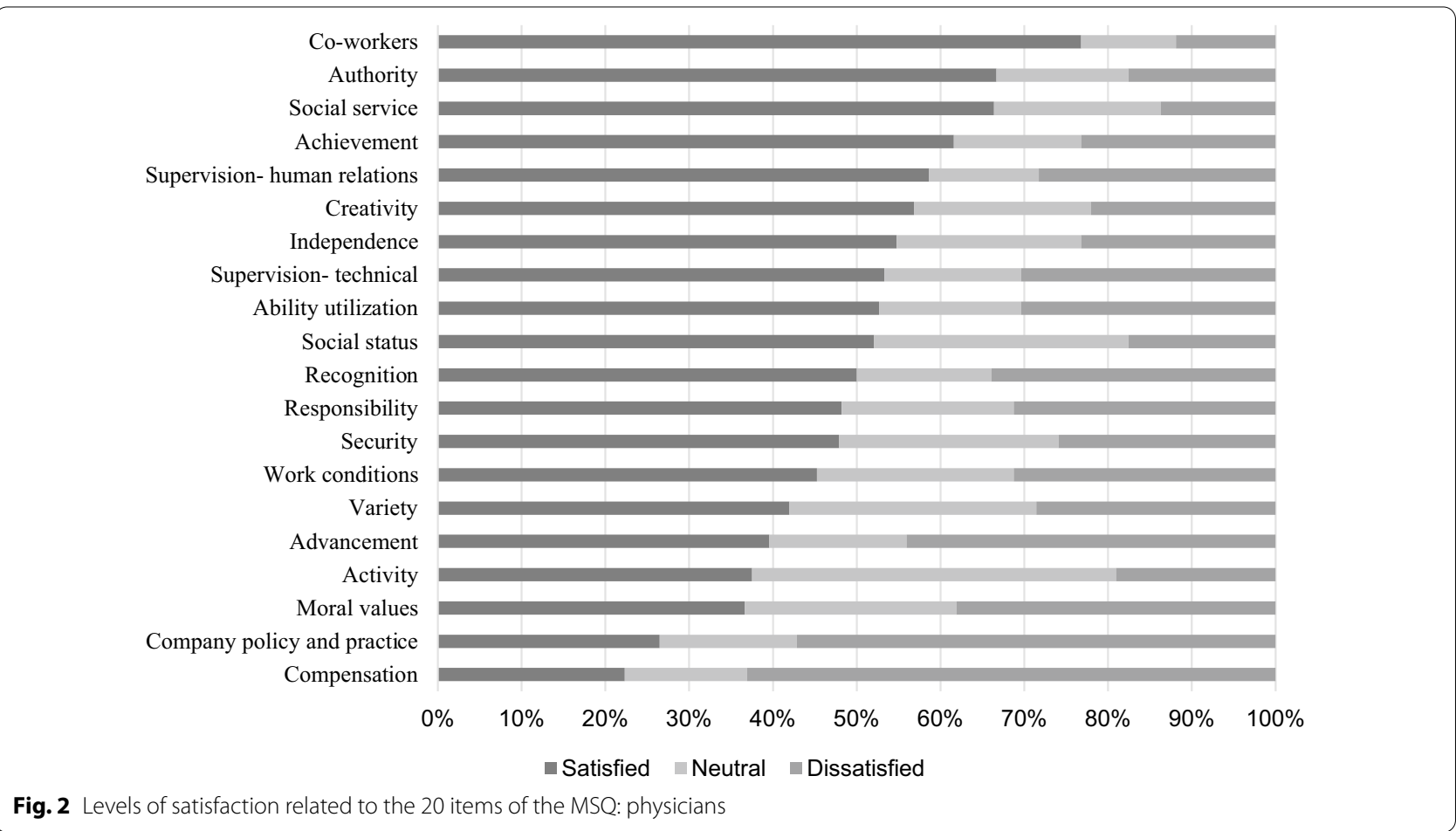




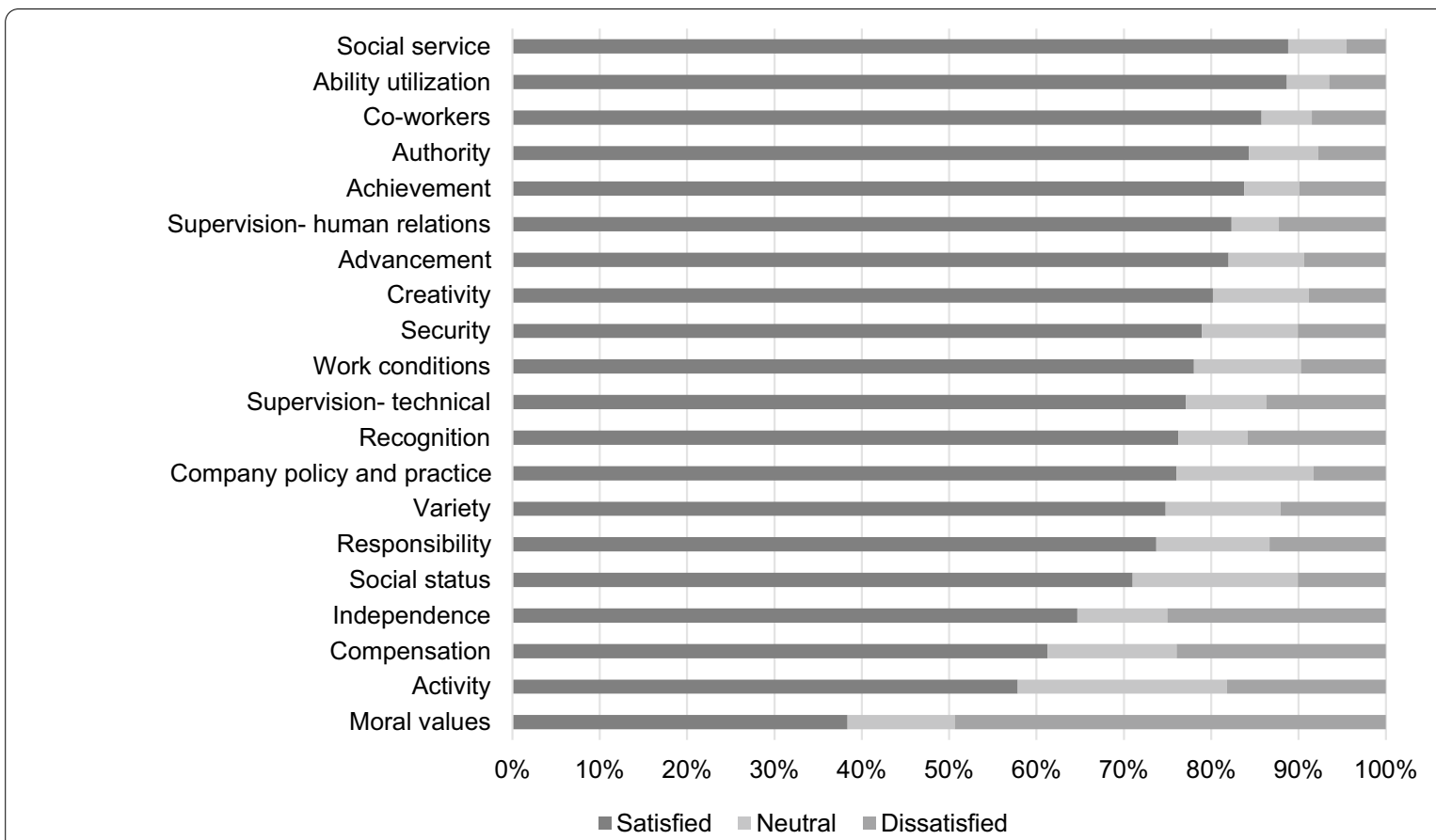

Fig. 3 Levels of satisfaction related to the 20 items of the MSQ: nurses

values, compensation, and independence items. Overall, physicians were more dissatisfied than nurses with compensation.

\section{Factors affecting job satisfaction Sociodemographic factors}

Sociodemographic factors included age, gender, education, and Turkish citizenship. A statistically significant difference was found in the mean general job satisfaction score between age groups $(p<0.003)$, education levels $(p<0.001)$, and citizenship categories $(p=0.002)$. The mean general job satisfaction score was highest among those aged 40-49 years. When analyzed by education level, job satisfaction was highest among those with high school education. Job satisfaction scores were higher for healthcare workers without Turkish citizenship than those with Turkish citizenship ( $p=0.002)$.

\section{Work characteristics}

The work characteristics assessed in this study were the number of patient consultations per day, access to resources (e.g., equipment and supplies) needed for, work and knowing how to use the available equipment and other materials. Job satisfaction scores were significantly different according to the number of consultations per day. Scores were highest among health workers who saw fewer than 21 patients per day $(p<0.001)$. There was a significant inverse relationship between the number of patients seen per day and job satisfaction scores $(p<0.001)$. Participants who reported having access to necessary resources also had significantly higher job satisfaction scores $(p<0.001)$.

\section{Work environment}

The factors used to assess the work environment of Syrian physicians and nurses were type of healthcentre and the participants' perceptions of teamwork and team management. Job satisfaction scores were significantly influenced by all three factors. The mean job satisfaction score was significantly lower for those working in extended RHCs $(p=0.007)$ and significantly higher among those who rated teamwork and team management as good. Those who rated teamwork as poor had job satisfaction scores 13 points lower than those who rated it as good and three points lower than those who rated it as average $(p<0.001)$.

\section{Profession, experience and income}

The mean job satisfaction scores were significantly higher in nurses than in the physicians $(p<0.001)$. Job satisfaction scores also differed significantly by the number of years they worked in Syria $(p<0.001)$ but not by the number of years working in Turkey $(p=0.190)$. Compared with the other categories for years worked in Syria, participants with over 10 years of experience had the highest mean job satisfaction scores. The 
mean job satisfaction score was directly associated with the perception of income earned from working in the RHCs (from poor to good; $p<0.001$ ). Compared with those who rated their income as good, the job satisfaction score was 7.7 points lower among those who rated it as poor and 3.4 points lower among for those who rated it as average.

Multiple linear regression analysis was used to determine which factors likely affected job satisfaction. Variables included in the analysis were age group, nationality, number of patients per day, type of health centre, teamwork, team management, job in Turkey, number of working years in Syria and income. Out of these factors, only profession in Turkey and perception of income, teamwork and team management were significantly associated with job satisfaction (Table 4).

\section{Discussion}

SHW in RHCs provide a critical human resource in response to the healthcare needs of 3.6 million Syrian refugees in Turkey. Previous field assessments among SHW showed that physicians and nurses valued the opportunity to work in Turkey and continuing to work in their profession [32]. They also appreciated the opportunity to earn their livelihood and serving their fellow Syrian refugees [32].

This study found that the job satisfaction levels were higher in nurses than in physicians. After completing

Table 4 Multiple regression analysis of factors associated with the general job satisfaction score

\begin{tabular}{|c|c|c|c|c|c|}
\hline \multirow[t]{2}{*}{ Variable } & \multirow[t]{2}{*}{$B$} & \multicolumn{2}{|l|}{$95 \% \mathrm{Cl}$} & \multirow[t]{2}{*}{ SE } & \multirow[t]{2}{*}{$p$ value } \\
\hline & & Lower bound & Upper bound & & \\
\hline \multicolumn{6}{|l|}{ Age group (years) (ref. $\geq 50$ ) } \\
\hline $20-29$ & -4.32 & -7.53 & -1.12 & 1.634 & $0.008^{*}$ \\
\hline $30-39$ & -4.61 & -7.28 & -1.94 & 1.361 & $0.001^{*}$ \\
\hline $40-49$ & -0.48 & -2.59 & 1.62 & 1.070 & 0.651 \\
\hline $\begin{array}{l}\text { Nationality (ref. Syrian with Turkish citizen- } \\
\text { ship) }\end{array}$ & 0.32 & -0.97 & 1.61 & 0.655 & 0.626 \\
\hline \multicolumn{6}{|l|}{ Education (ref. High school) } \\
\hline Undergraduate degree & -0.52 & -2.45 & 1.42 & 0.984 & 0.600 \\
\hline Masters/postgraduate degree & -0.31 & -3.12 & 2.50 & 1.432 & 0.829 \\
\hline \multicolumn{6}{|l|}{ Number of patients/day (ref.<20) } \\
\hline $21-40$ & -0.81 & -3.26 & 1.63 & 1.247 & 0.515 \\
\hline $41-60$ & -0.45 & -2.97 & 2.07 & 1.285 & 0.725 \\
\hline$\geq 61$ & -1.52 & -4.19 & 1.15 & 1.361 & 0.265 \\
\hline \multicolumn{6}{|l|}{ Type of health centre (ref. RHTC) } \\
\hline $\mathrm{RHC}$ & -1.65 & -3.93 & 0.63 & 1.161 & 0.156 \\
\hline Extended RHC & -2.00 & -5.38 & 1.38 & 1.721 & 0.245 \\
\hline \multicolumn{6}{|l|}{ Teamwork (ref. Good) } \\
\hline Poor & -13.44 & -18.11 & -8.77 & 2.379 & $0.000^{*}$ \\
\hline Average & -3.82 & -6.13 & -1.51 & 1.178 & $0.001^{*}$ \\
\hline \multicolumn{6}{|l|}{ Team management (ref. Good) } \\
\hline Poor & -15.85 & -18.63 & -13.08 & 1.412 & $0.000^{*}$ \\
\hline Average & -9.31 & -11.27 & -7.35 & 0.998 & $0.000^{*}$ \\
\hline \multicolumn{6}{|l|}{ Profession (ref. Nurse/midwife) } \\
\hline General physician & -6.84 & -8.81 & -4.88 & 1.000 & $0.000^{*}$ \\
\hline Specialist physician & -6.60 & -9.59 & -3.62 & 1.522 & $0.000^{*}$ \\
\hline \multicolumn{6}{|l|}{ Years worked in Syria (ref. > 10) } \\
\hline $0-5$ & 1.99 & -0.37 & 4.35 & 1.202 & 0.099 \\
\hline $6-10$ & 2.26 & 0.05 & 4.48 & 1.130 & $0.045^{*}$ \\
\hline \multicolumn{6}{|l|}{ Income (ref. Good) } \\
\hline Poor & -7.79 & -9.77 & -5.81 & 1.009 & $0.000^{*}$ \\
\hline Average & -3.24 & -4.77 & -1.72 & 0.777 & $0.000^{*}$ \\
\hline
\end{tabular}


adaptation training, Syrian nurses continue to work as nurses in RHCs but perhaps the more advanced health system in Turkey provides more opportunities to apply their skills, increasing job satisfaction. In comparison, physicians working in RHCs provide only primary healthcare services, limiting their ability to use their skills, especially for specialist physicians. Physicians who had trained and worked as a specialist in Syria but were working as general physicians in Turkey had a lower job satisfaction than those who continued to work as specialists in Turkey. Although the difference between satisfaction scores in our study was not statistically significant, previous studies reported that specialization and work engagement were associated with job satisfaction [23, 33]. Indeed, the profession in Turkey was a significant factor for job satisfaction for healthcare workers in RHCs. The RHCs provide a time-bound response to health service provision to Syrian refugees in Turkey. However, there is no mechanism for professional advancement for SHW; unsurprisingly, physicians expressed dissatisfaction with the lack of opportunities for advancement. Other studies have demonstrated that opportunities for advancement affect staff motivation and job satisfaction among healthcare workers [34]. Improving professional engagement for physicians in RHCs could enhance their job satisfaction levels, motivation, and intention to stay on the job and positively impact job performance in terms of the effectiveness and quality of care and patient satisfaction.

The mean job satisfaction score increased with the perception of income adequacy. Most study participants said their income was average. Evidence of inadequate income was provided by the low rating for compensation by both nurses and physicians, but particularly by physicians. Income was a significant predictor of job satisfaction. A qualitative study on factors affecting the employability of SHW revealed that the cost of living, not having other salary supplements, the costs of transportation, lunch and child care, and not being allowed to supplement their work with private practice limited the adequacy of their income from RHCs [32]. These factors may explain the importance of income in determining job satisfaction in healthcare workers in RHCs. In addition, comparing their income with Turkish physicians working in hospitals and not those working in primary health care may skew their perception of income adequacy. Studies conducted elsewhere showed that remuneration influences job satisfaction [35] and that non-monetary incentives increased professional and performance satisfaction among physicians $[22,35]$. In fact, one study argued that non-monetary incentives could be more important than monetary incentives in supplementing physicians' incomes [36]. Annual cost of living adjustments to the salaries of healthcare workers in RHCs coupled with non-financial incentives could improve job satisfaction.

Physicians and nurses considered that co-workers get along with each other to a satisfactory extent, which indicates good teamwork at RHCs. The study also found that the quality of teamwork is a significant determinant of job satisfaction. Relationships between co-workers shape the work environment and influence job satisfaction in general. A previous study demonstrated that job satisfaction in the delivery of healthcare was predicted by organizational culture and teamwork [37]. Others found that collaboration between workers and collegial relationships were associated with job satisfaction [26, 37-39]. Therefore, maintaining good teamwork in RHCs is critical to maintaining a supportive working environment for the health workers.

Management and leadership are essential for delivering healthcare services. Poor management of planning and coordination processes, care processes, human resources, and information flow negatively impact the work environment and job satisfaction in healthcare workers. This study found that the quality of team management was significantly associated with job satisfaction. Compared with those who rated team management as good, job satisfaction levels were 15.9 points lower in healthcare workers who rated team management as poor and 9.3 points lower in those who rated it average. Other studies also found that the quality of leadership was positively associated with physician satisfaction $[25$, 40]. Another found an association between the quality of nurse management at the unit level and job satisfaction [26]. Therefore, strengthening leadership and management in RHCs may positively impact the job satisfaction of SHW; hence, good RHC management may lead to positive outcomes for health workers and the quality of health service delivery.

Patient workload may have an impact on the job satisfaction of health workers. A previous report found that the nursing workload and staffing correlate strongly with the quality of outcomes for patients, nurses, and the organization [41]. Other evidence indicated that increased patient workload or work-related stress could decrease job satisfaction for physicians [42, 43], which impacts individual and organizational performance, absenteeism, and turnover [42]. Similarly, in the present study, the mean job satisfaction score decreased with increasing patient load. The dissatisfaction may be explained by the difference in working hours between Syria and Turkey, with fewer working hours in Syria. However, when other factors were considered, the number of patients seen per day did not significantly affect job 
satisfaction, suggesting that, at least for this population, it may not be an important factor.

Job satisfaction was higher in health workers who did not yet have Turkish citizenship, but the association was not significant when other factors were considered. Acquiring citizenship might be expected to lead to greater job satisfaction, because it provides opportunities for integration into the labor market. However, the higher satisfaction levels of participants without Turkish citizenship might simply indicate a more positive response or information bias by these participants; therefore, this result should be interpreted cautiously.

Both nurses and physicians expressed dissatisfaction on the professional moral values item of the MSQ, but further examination is required to determine the explanation. However, differences in the working context might present the healthcare workers with issues that challenge the values they hold as foreigners.

This was the first study to examine job satisfaction among SHW in RHCs in Turkey. Including all SHW and the response of rate of $56.5 \%$ were major strengths of the study. A self-administered questionnaire and the possibility of information bias should be considered when interpreting the results. However, the overall data quality suggests that evidence obtained in the study can be used to improve job satisfaction in RHCs and makes a valuable addition to the body of knowledge on refugee healthcare workers. Although factors influencing job satisfaction were identified, these can only explain some of the variation in the job satisfaction score. Further research could determine other factors that influence job satisfaction among Syrian health workers. In addition, comparative studies of Turkish and Syrian health workers and studies on labor market integration of Syrian health workers could shade more light on challenges and opportunities for strengthening the health workforce. Researchers should also focus on the labor market dynamics and the close connection between the healthcare workers' job satisfaction and patient satisfaction.

\section{Conclusions}

This study showed that job satisfaction for SHW in Turkey was determined by profession in Turkey, income, teamwork, and team management. In this and other contexts with refugee healthcare workers, human resources management should consider developing evidence-informed policies to accommodate refugee healthcare workers with equity and balance, providing opportunities for matching job placements with training specialization of refugees, maintaining good leadership and teamwork, and remuneration that accounts for the cost of living coupled with non-financial incentives. Establishing an integrated, fair work environment could contribute to maintaining a high level of job satisfaction in refugee healthcare workers and, consequently, performance levels and patient satisfaction.

\section{Abbreviations \\ Cl: Confidence interval; MSQ: Minnesota Satisfaction Questionnaire; RHC: Refugee Healthcentre; RHTC: Refugee health trainingcentre; SD: Standard deviation; SIHHAT: Improving the health status of the Syrian population under temporary protection and related services provided by Turkish authorities (project).}

\section{Acknowledgements}

We would like to thank the management of the WHO Country Office in Turkey and Kanuni Keklik of the Ministry of Health of the Republic of Turkey for their leadership and guidance in implementing the study. We also thank Pelin Cebeci, Çetin Doğan Dikmen, Elif Göksu, Nurtaç Kavukcu, Melda Keçik, Kadriye Küçükbalci, Altin Malaj and Mustafa Bahadir Sucakli of WHO and Mehmet Balcılar, Alpaslan Girayalp, Burçin Tahtacıoğlu and Sarp Üner of PGlobal Global Advisory and Training Services for their valuable contribution in implementing the study.

\section{Authors' contributions}

MZ and OCE were responsible for the concept and design of the study. MZ led the design, data analysis, interpretation of results and writing the manuscript. OCE supported data analysis and, interpretation of results. $\mathrm{HO}$ lead the field implementation of the study. All authors reviewed the manuscript and contributed to the final submission. All authors read and approved the final manuscript.

\section{Authors' information}

Monica Zikusooka is a Monitoring and Evaluation Officer in Refugee Health Programme, WHO Country Office in Turkey, WHO Regional Office for Europe. Omur Cinar Elci is a Consultant in Refugee Health Programme, WHO Country Office in Turkey, WHO Regional Office for Europe.

Habibe Özdemir is a Health Expert in Ministry of Health of the Republic of Turkey.

\section{Funding}

This study was funded by the Government of Germany through KfW Development Bank (BMZ ID: 201740828). The funder was not involved in the design or implementation of the study, neither was the funder involved in writing the manuscript.

\section{Availability of data and materials}

The data sets generated and/or analyzed during the current study are available in the [WHO] repository.

\section{Declarations}

\section{Ethics approval and consent to participate}

Ethical approval for this study (Protocol ID: ERC.0003208) was obtained from the WHO Ethical Review Committee on on 25.09.2019 and Gazi University Ethical Board (Issue number 91610558-604.01.02) on 11.09.2019. All participants included in the study gave consent to participate.

\section{Consent for publication}

Not applicable.

\section{Competing interests}

The authors declare that they have no competing interests.

\section{Author details}

${ }^{1}$ Refugee Health Programme, WHO Country Office in Turkey, WHO Regional Office for Europe, Ankara, Turkey. ${ }^{2}$ SIHHAT Project, Migrant Health Department, Ministry of Health of the Republic of Turkey, Ankara, Turkey. 
Received: 2 September 2021 Accepted: 3 November 2021

Published online: 14 November 2021

\section{References}

1. Ministry of Interior Directorate General of Migration Management. Temporary protection. https://en.goc.gov.tr/temporary-protection27. Accessed 20 July 2021

2. Bucken-Knapp G, Fakih Z, Spehar A. Talking about integration: the voices of Syrian refugees taking part in introduction programmes for integration into Swedish Society. Int Migr. 2019;57(2):221-34.

3. Khan-Gökkaya S, Mösko M. Labour market integration of refugee health professionals in Germany: challenges and strategies. Int Migr. 2020;59:105-26.

4. Jirovsky E, Hoffmann K, Maier M, Kutalek R. Why should I have come here-a qualitative investigation of migration reasons and experiences of health workers from sub-Saharan Africa in Austria. BMC Health Serv Res. 2015;15(1):1-12.

5. Leblanc Y, Bourgeault IL, Neiterman E. Comparing approaches to integrating refugee and asylum-seeking healthcare professionals in Canada and the UK. Healthc Policy | Polit Santé. 2013;9(1):126-38.

6. Rabben L. Credential recognition in the United States for Foreign Professionals. Washington, DC; 2013. https://www.migrationpolicy.org/pubs/ UScredentialrecognition.pdf.

7. Khan-Gökkaya S, Mösko M. Process- and outcome evaluation of an orientation programme for refugee health professionals. Med Educ Online. 2020;25(1):1811543. https://doi.org/10.1080/10872981.2020.1811543.

8. Dumont J, Liebig T, Peschner J, Tanay F, Xenogiani T. How are refugees faring on the labour market in Europe ?. 2016. Report No.: 1/2016. https:// ec.europa.eu/social/main.jsp?catld=738\&langld=en\&publd=7921\&furth erPubs=yes.

9. Kureshi S, Namak SY, Sahhar F, Mishori R. Supporting the integration of refugee and asylum seeking physicians into the US Health Care System. J Grad Med Educ. 2019:11(4):22-9.

10. International Organization for Migration. Crushed Hopes. Crushed Hopes. 2013. https://publications.iom.int/system/files/pdf/crushed_hopes_3jan2 013.pdf.

11. Cohn S, Alenya J, Murray K, Bhugra D, De Guzman JSU. Experiences and expectations of refugee doctors: qualitative study. Br J Psychiatry. 2006;189:74-8.

12. Butt MF, Salmon L, Mulamehic F, Hixon A, Moodambail AR, Gupta S. Integrating refugee healthcare professionals in the uk national health service: experience from a multi-agency collaboration. Adv Med Educ Pract. 2019;10:891-6.

13. Maria Vincenza Desiderio. Transatlantic council on migration: challenges and policy options. 2016. https://www.migrationpolicy.org/sites/default/ files/publications/TCM-Asylum-Desiderio-FINAL.pdf.

14. Namak S, Sahhar F, Kureshi S, El-Rayess F, Mishori R. Integrating refugee doctors into host healthcare systems. Spec Sect Econ Rights Access to Work. 2018;(58):16-8. http://www.fmreview.org/sites/fmr/files/FMRdo wnloads/en/economies.pdf

15. Klingler C, Marckmann G. Difficulties experienced by migrant physicians working in German hospitals: a qualitative interview study. Hum Resour Health. 2016;14(1):1-13. https://doi.org/10.1186/s12960-016-0153-4.

16. Abubakar I, Aldridge RW, Devakumar D, Orcutt M, Burns R, Barreto ML, et al. The UCL-Lancet Commission on Migration and Health: the health of a world on the move. Lancet. 2018;392(10164):2606-54.

17. Hohn MD, Witte JC. Immigrants in health care-keeping Americans healthy through care and innovation. 2016;(June). file:///Users/nhoriebhest.pierre/Downloads/health_care_report_FINAL_20160629.pdf

18. Linzer M, Manwell LB, Williams ES, Bobula JA, Brown RL, Varkey AB, et al. Working conditions in primary care: physician reactions and care quality. Ann Intern Med. 2009;151(1):28-36, W6-9.

19. Haas JS, Cook EF, Puopolo AL, Burstin HR, Cleary PD, Brennan TA. Is the professional satisfaction of general internists associated with patient satisfaction? J Gen Intern Med. 2000;15(2):122-8.

20. Janicijevic I, Seke K, Djokovic A, Filipovic J. Healthcare workers satisfaction and patient satisfaction - where is the linkage? Hippokratia. 2013;17(2):157-62.
21 Kvist T, Voutilainen A, Mäntynen R, Vehviläinen-Julkunen K. The relationship between patients' perceptions of care quality and three factors: nursing staff job satisfaction, organizational characteristics and patient age. BMC Health Serv Res. 2014;14(1):466.

22. Dawson J. Links between NHS staff experience and patient satisfaction: Analysis of surveys from 2014 and 2015. Health Serv Deliv Res. 2018;2(50):1-52. www.england.nhs.uk/about/equality/equality-hub/ equality.

23. DiMatteo MR, Sherbourne CD, Hays RD, Ordway L, Kravitz RL, McGlynn EA, et al. Physicians' characteristics influence patients' adherence to medical treatment: results from the medical outcomes study. Health Psychol. 1993;12(2):93-102.

24. De Simone S, Planta A, Cicotto G. The role of job satisfaction, work engagement, self-efficacy and agentic capacities on nurses'turnover intention and patient satisfaction. Appl Nurs Res. 2018;39(November 2017):130-40. https://doi.org/10.1016/j.apnr.2017.11.004

25. Domagała A, Bała MM, Storman D, Peña-Sánchez JN, Świerz MJ, Kaczmarczyk M, et al. Factors associated with satisfaction of hospital physicians: a systematic review on european data. Int J Environ Res Public Health. 2018:15(11):2546.

26. Van Bogaert $P$, Timmermans $O$, Weeks $S M$, van Heusden $D$, Wouters $K$, Franck E. Nursing unit teams matter: impact of unit-level nurse practice environment, nurse work characteristics, and burnout on nurse reported job outcomes, and quality of care, and patient adverse events-a crosssectional survey. Int J Nurs Stud. 2014;51(8):1123-34. https://doi.org/10. 1016/j.jinurstu.2013.12.009.

27 Lu H, Zhao Y, While A. Job satisfaction among hospital nurses: a literature review. Int J Nurs Stud. 2019;94:21-31.

28. Doede M. Race as a predictor of job satisfaction and turnover in US nurses. J Nurs Manag. 2017;25(3):207-14.

29 Carthon JMB, Travers JL, Hounshell D, Udoeyo I, Chittams J. Disparities in nurse job dissatisfaction and intent to leave: implications for retaining a diverse workforce. J Nurs Adm. 2021;51(6):310-7.

30. Gebregziabher D, Berhanie E, Berihu H, Belstie A, Teklay G. The relationship between job satisfaction and turnover intention among nurses in Axum comprehensive and specialized hospital Tigray, Ethiopia. BMC Nurs. 2020;19(1):1-8

31. Weiss JD, Dawis RV, England GW, Lofquist HL. Monograph XXII—Manual for the MN Satisfaction Questionnaire.pdf. 1967. https://vpr.psych.umn. edu/sites/vpr.umn.edu/files/files/monograph_xxii___manual_for_the_ mn_satisfaction_questionnaire.pdf.

32. WHO Regional Office for Europe. Factors affecting the employability of refugee Syrian healthcare professionals in Turkey. 2021. https://www. euro.who.int/en/countries/turkey/publications/factors-affecting-theemployability-of-refugee-syrian-health-care-professionals-in-turkey-2021.

33. Mathauer I, Imhoff I. Health worker motivation in Africa: the role of non-financial incentives and human resource management tools. Hum Resour Health. 2006;4:1-17.

34. Khunou SH, Davhana-Maselesele M. Level of job satisfaction amongst nurses in the North-West Province, South Africa: post occupational specific dispensation. Curationis. 2016:39(1):1438.

35. Lambrou P, Kontodimopoulos N, Niakas D. Motivation and job satisfaction among medical and nursing staff in a Cyprus public general hospital. Hum Resour Health. 2010;8:1-9.

36 Janus K, Amelung VE, Gaitanides M, Schwartz FW. German physicians "on strike" - shedding light on the roots of physician dissatisfaction. Health Policy (New York). 2007;82(3):357-65.

37. Körner M, Wirtz MA, Bengel J, Göritz AS. Relationship of organizational culture, teamwork and job satisfaction in interprofessional teams Organization, structure and delivery of healthcare. BMC Health Serv Res. 2015;15(1):1-12. https://doi.org/10.1186/s12913-015-0888-y.

38. Peña-Sánchez JN, Lepnurm R, Morales-Asencio JM, Delgado A, Domagała A, Górkiewicz M. Factors identified with higher levels of career satisfaction of physicians in Andalusia, Spain. Health Psychol Res. 2014;2(2):1527.

39. Chang W, Ma J, Chiu H, Lin K, Lee P. Job satisfaction and perceptions of quality of patient care, collaboration and teamwork in acute care hospitals. J Nurs Manag. 2009;65(9):19461955.

40 Mache S, Vitzthym K, Klapp BF, Danzer G. Surgeons' work engagement: Influencing factors and relations to job and life satisfaction. Surgeon. 2014;12(4):181-90. https://doi.org/10.1016/j.surge.2013.11.015. 
41. Pearson A, Pallas L, Thomson D, Doucette E, Tucker D, Wiechula R, et al. Systematic review of evidence on the impact of nursing workload and staffing on establishing healthy work environments. Int J Evid Based Healthc. 2004;4(4):337-84.

42. Williams ES, Rondeau KV, Xiao Q, Francescutti LH. Heavy physician workloads: impact on physician attitudes and outcomes. Health Serv Manag Res. 2007:20(4):261-9.

43. Semachew A, Belachew T, Tesfaye T, Adinew YM. Predictors of job satisfaction among nurses working in Ethiopian public hospitals,
2014: Institution-based cross-sectional study. Hum Resour Health. 2017;15(1):1-8

\section{Publisher's Note}

Springer Nature remains neutral with regard to jurisdictional claims in published maps and institutional affiliations.
Ready to submit your research? Choose BMC and benefit from:

- fast, convenient online submission

- thorough peer review by experienced researchers in your field

- rapid publication on acceptance

- support for research data, including large and complex data types

- gold Open Access which fosters wider collaboration and increased citations

- maximum visibility for your research: over $100 \mathrm{M}$ website views per year

At BMC, research is always in progress.

Learn more biomedcentral.com/submissions 